\title{
EVALUASI CRITICAL PARAMETER KOMPRESOR MULTISTAGE UNTUK MENINGKATKAN PRODUKSI MIGAS SALAH SATU ANJUNGAN OFFSHORE DI KALIMANTAN TIMUR
}

\author{
Sunarji*1 $^{1}$, Ilham Fahrurozi ${ }^{2}$, Ivan Susanyo ${ }^{3}$ \\ ${ }^{1}$ Jurusan Teknik Mesin, Fakultas Teknik, Universitas Tridharma, Balikpapan \\ ${ }^{2,3}$ Praktisi Perusahaan Migas Balikpapan \\ e-mail: ${ }^{* 1}$ sunarii1977@gmail.com,
}

\begin{abstract}
Abstrak
Penelitian ini memperkenalkan metode pendekatan statistik untuk mengetahui parameter-parameter yang berpengaruh signifikan terhadap kinerja kompresor multistage dalam berbagai kondisi operasi yang mempengaruhi proses produksi minyak dan gas . Korelasi empiris memberikan pendekatan baru untuk mengetahui parameter kritikal dalam kompresor dan kemampuan prediksi terhadap peningkatan produksi. Metode ini telah diterapkan di kompresor multistage di salah satu Anjungan Offshore di Wilayah Kalimantan Timur. Parameter-parameter yang di analisis pada kompresor multistage ( C301 A/B, C302 A/C dan C303 A/B) antara lain Suction Pressure, Suction Temperature, Discharge Pressure, Discharge Temperature, Suction Flow, Suction Temperature, Speed NGP dan Speed NPT . Metode statistik yang digunakan antara lain Regression Analysis, Analysis of Variance (ANOVA) dan Main Effect Plot (MEP) dengan menggunakan software MINITAB. Hasil analisis menunjukkan parameter yang berpengaruh signifikan di kompresor C301 $A / B$ adalah suction pressure dan speed, sedangkan untuk kompresor C302 A/C parameter yang berpengaruh signifikan adalah suction pressure, discharge pressure dan suction flow. Hasil berbeda ditunjukkan oleh kompresor C303 A/B dimana hanya discharge pressure yang berpengaruh signifikan. Hasil analisis ini juga mampu mengevaluasi serta memprediksi model optimum dari korelasi dan kombinasi parameter-parameter yang signifikan tersebut sehingga bisa gunakan sebagai acuan untuk melakukan optimasi setting parameter di proses produksi sehingga meningkatkan produksi dari sumur.
\end{abstract}

Kata kunci-Critical Parameter, Kompresor Multistage,Pendekatan Statistik

\begin{abstract}
This research introduce a statistical approach to know significant parameters on ultistage compressor in different states operation that affect to production process of oil and gas. The correlation empirical give a new approach to know critical parameters in the compressor and prediction ability to increase production. This method has been implemented in multistage compressor in one of offshore platform at East Kalimantan. Parameters are analyzed on multistage compressor such as : Suction Pressure, Suction Temperature, Discharge Pressure, Discharge Temperature, Suction Flow, Suction Temperature, Speed NGP dan Speed NPT. Statistical methods using Regression Analysis, Analysis of Variance (ANOVA) dan Main Effect Plot (MEP) with MINITAB software. The Result of analysis shows parameter significant on Compressor C301 A/B are suction pressure and speed, while for Compressor C302 A/C parameter that significant is suction pressure, discharge pressure and suction flow. Different outcome indicated by compressor C303 A/B that only discharge pressure parameter influential significant. The result of analysis is also able to evaluate and predict model optimum correlation and combination significant parameters so the model able to use as the reference for optimize setting parameter at the production process to increase output production wells.
\end{abstract}

Keywords_- Critical Parameter, Multistage Compressor, Statistical Approach 


\section{PENDAHULUAN}

Salah satu Anjungan Offshore Kalimantan Timur terdiri dari living quarters platform, production platform dan compressor platform .

Compressor platform terdiri dari:

- 1st Stage Compressor

- Inlet Scrubber V-1101

- 2nd Stage Inlet Scrubber V-1102

- 2nd Stage Outlet Knockout Drum $\mathrm{V}-1103$

- Gas Lift Compressor

- Knockout Drum V-1105

- 1st Stage Gas Compressors C-301 $A / B$

- 2nd Stage Gas Compressors C$302 \mathrm{~A} / \mathrm{C}$

- 3rd Stage Produced Gas Compressors C-303A/B

- Fuel Gas Knockout Drum V-1106

- Fuel Gas Filter F-1108 A/B, F$1109 \mathrm{~A} / \mathrm{C}, \mathrm{F}-1110$ and $\mathrm{F}-1111$

Gas dari Inlet Gas Scrubber (V-108-P) dialirkan ke 1st Stage Compressor Inlet Scrubber (V-1101) kemudian dihisap oleh 1st Stage Gas Compressor C-301A/B untuk dikompresi. Selanjutnya gas dialirkan ke 2nd Stage Inlet Scrubber ( $\mathrm{V}$ 1102) dan dikompresi lebih tinggi lagi oleh 2nd Stage Gas Compressor C-302 A/C. Discharge compressor C-302 A/C akan mengalir ke 2nd Stage Outlet Knockout Drum (V-1103) dan kemudian mengalir ke santan terminal dan dikompresi ke 3rd Stage Gas Compressor (C-303 A/B) sebagai gas lift, dan selain itu discharge $2^{\text {nd }}$ compressor sebagian digunakan dialirkan ke fuel gas system. Gas yang digunakan sebagai gas lift akan dihisap oleh C-303 A/B untuk dikompresi dan selanjutnya akan mengalir ke Gas Lift Compressor Knockout Drum (V-1105). Outlet V-1105 akan dialirkan ke gas lift header masing-masing remote. Gas yang digunakan sebagai fuel gas akan mengalir ke Fuel Gas Knockout Drum (V-1106). Kemudian gas akan mengalir ke Fuel Gas
Filter (F-1108 A/B, F-1108 A/C, F-1110, $F-1111)$ dan selanjutnya akan mengalir ke gas turbine masing-masing compressor.

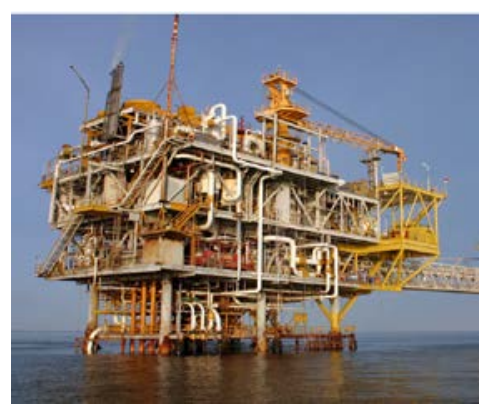

Gambar 1: Compressor Platform (CP)

Sumber : Alfian Photography,2006

\section{METODE PENELITIAN}

Data parameter yang di analisis pada compressor multistage antara lain Suction Pressure, Suction Temperature, Discharge Pressure, Discharge Temperature, Suction Flow, Suction Temperature, Speed NGP dan Speed NPT. Data ini di unduh (download) dari Historian compressor multistage yang terhubung dengan telemetry system.

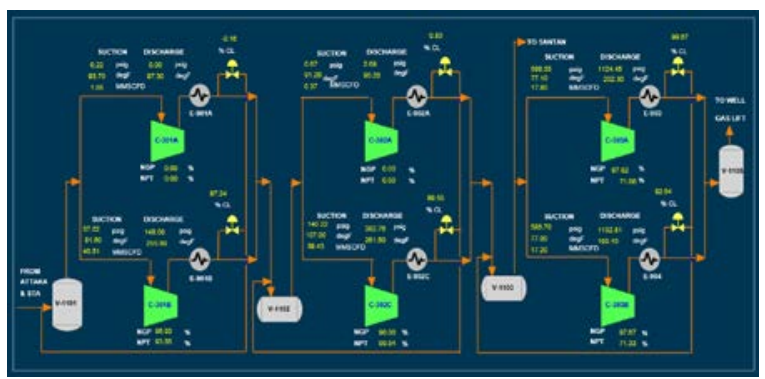

Gambar 2. Historian Compressor.

Sumber: Olahan Sendiri, 2019

Metode yang digunakan dalam analisis ini adalah Regression Analysis, Analysis of Variance (ANOVA) dan Main Effect Plot (MEP). Langkah-langkah untuk mendapatkan korelasi antara parameter Compressor Multistage ini adalah dengan mencari persamaan dari parameterparameter yang dianalisis terhadap 
response dengan menggunakan program Minitab.

Ada 4 langkah dalam Analisis :

1) Memasukkan data yang diunduh dari Historian compressor multistage dengan menginput langsung ke MINITAB atau copy dan paste dari excel file data ke dalam MINITAB Sheet.

2) Menjalankan program Minitab dengan mengklik Stat >Basic Statistics > Graphical Summary untuk mengetahui validitas data yang akan diolah, Apabila validitas data belum terpenuhi maka perlu diambil data lagi atau identifikasi penyebab ketidaknormalan data dan atau dengan transformasi data mengunakan Johnson Transformation atau Box Cox Transformation yang selanjutnya dilakukan analisis kembali hingga data valid ( ditandai dengan nilai $P$ Value lebih besar atau sama dengan 0.05).

3) Analisis data untuk melihat korelasi antar parameter Compressor Multistage dengan menjalankan program Minitab dengan mengklik Stat $>$ Anova > Main Effect plot.

4) Interprestasi hasil dari analisis statistik dengan memperhatikan nilai $P$ Value, nilai $R$-Square dan Main Effect Plot serta persamaan regresi yang dihasilkan dari analisis data.

\section{HASIL DAN PEMBAHASAN}

Dari data yang diolah dengan menggunakan metode Regression Analysis, Analysis of Variance (ANOVA) dan Main Effect Plot (MEP) diperoleh persamaan regresi di Compressor Multistage sebagai berikut:

1) Persamaan Regresi C301 A/B.

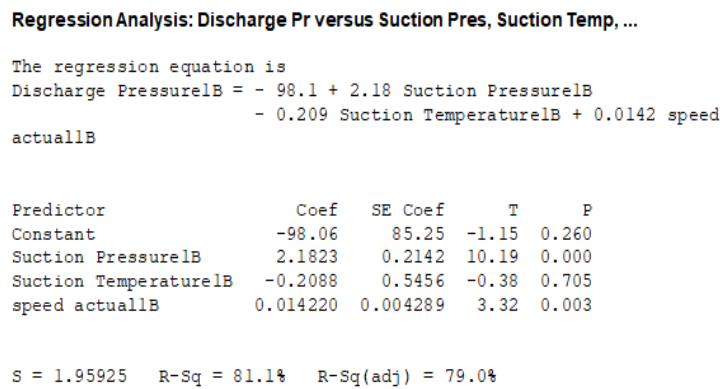

2) Persamaan Regresi C302 A/C

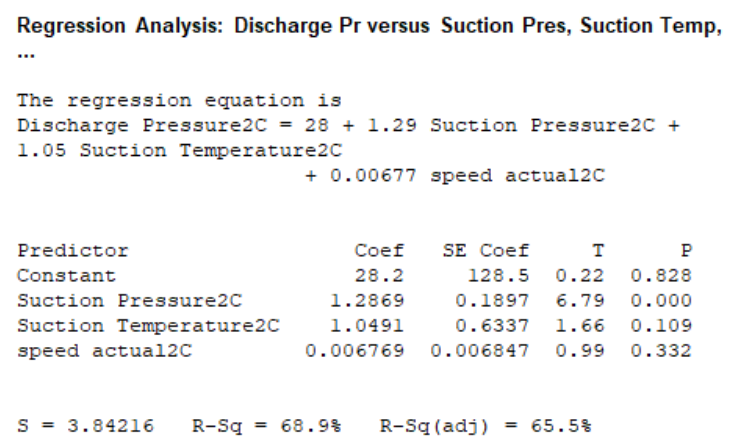

3) Persamaan Regresi C303 A/B

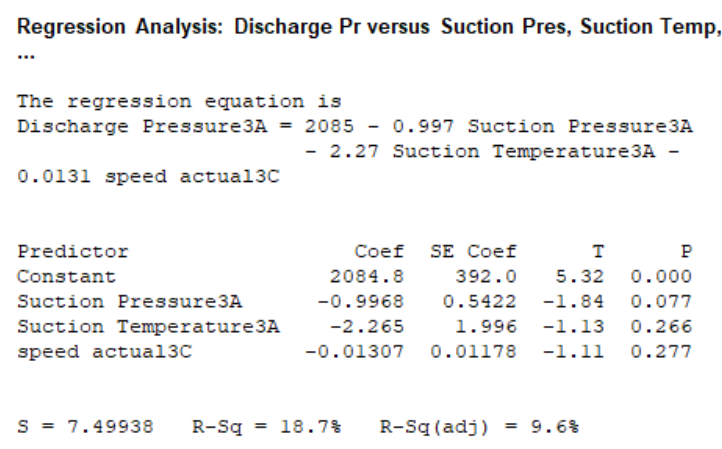

Regression Analysis: Discharge Pr versus Suction Pres, Suction Temp, ...

The regression equation is

Discharge Pressure $3 \mathrm{~B}=2048-1.14$ Suction Pressure $3 \mathrm{~B}$ 2.64 Suction Temperature3B -0.0026 speed actual3B

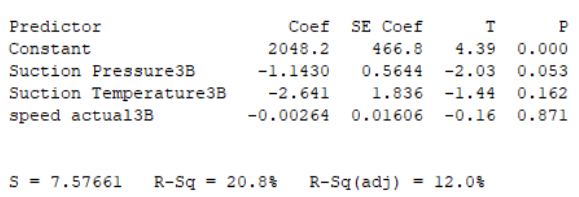

Dari persamaan regresi C301 A/B diperoleh bahwa parameter yang berpengaruh signifikan terhadap Discharge Pressure C301 A/B adalah Suction Pressure dan Speed. ( P-value 
$<0.05$ ),sedangkan parameter Suction Temperature tidak berpengaruh tidak signifikan ( $P$-value 0.705). Persamaan regresi C301 A/B juga dapat disimulasikan untuk memprediksi pengaruh penurunan Suction Pressure terhadap Discharge Pressure. Penurunan Suction Pressure di C301 A/B sebesar 10\% akan menurunkan Discharge Pressure sebesar 5\%.

Untuk C302 A/C diperoleh parameter yang berpengaruh signifikan terhadap Discharge Pressure C302 A/C adalah Suction Pressure ( $\mathrm{P}$ Value $<0.05$ ), sedangkan Suction Temperature dan Speed tidak berpengaruh tidak signifikan ( $P$ value 0.103 dan 0.33).Dari hasil analisis juga diperoleh bahwa Discharge Pressure dan Discharge flow perlu dimonitor mengikuti persyaratan (requirement) dan proses selanjutnya dari C301 A/C ini.

Persamaan Regresi C303 A/B diperoleh hasil bahwa parameter Suction Pressure, Suction Temperature dan Speed berpengaruh tidak signifikan terhadap Discharge Pressure C303 A/B ( P-Value $>0.05)$. Nilai Discharge Pressure C303A/B sangat menentukan dan berpengaruh terhadap gas lift yang diinjeksikan ke dalam sumur.Hasil analisis dari nilai Discharge Pressure C303A/B perlu dijaga diatas 1100 Psig untuk memberikan hasil produksi yang optimum.

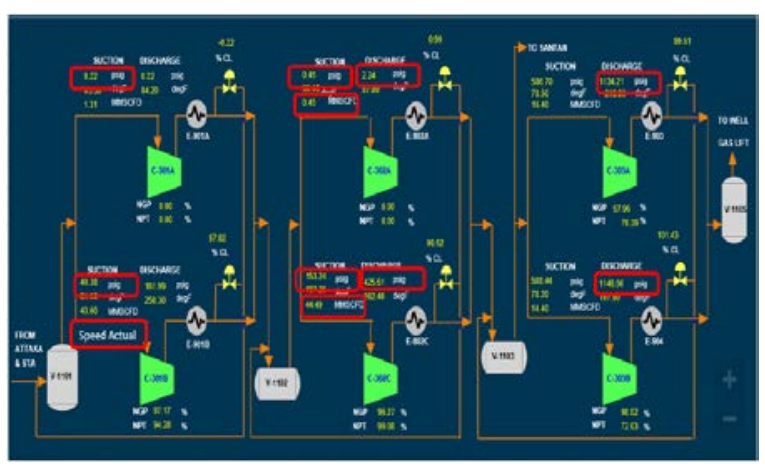

Gambar 3.Critical Parameter Compressor

Sumber : Olahan Sendiri ,2019

Implementasi dari analisis persamaan regresi diatas, Sumur FS di salah satu Anjungan offshore di Wilayah Kalimantan
Timur dengan tingkat kepercayaan yang tinggi untuk diturunkan nilai suction pressure dari sebelumnya rata-rata 35 sampai dengan 40 Psig menjadi rata-rata 20 sampai dengan 25 Psig dengan hasil peningkatan produksi minyak di sumur FS sebesar 59 barrel per hari dan peningkatan produksi gas 1.5 MMSCFD ( setara dengan 39 milyar rupiah per tahun).

\section{KESIMPULAN}

Dari hasil dan uraian tersebut didapatkan kesimpulan sebagai berikut :

- Parameter yang berpengaruh signifikan terhadap discharge pressure di compressor Multistage Anjungan offshore ini adalah C301A/B : Suction Pressure dan Speed; C302A/C : Suction Pressure, sedangkan untuk C303 A/B parameter Suction Pressure, Suction Temperature dan Speed berpengaruh tidak signifikan terhadap Discharge Pressure C303 $\mathrm{A} / \mathrm{B}$

- Penurunan $10 \%$ dari suction Pressure di Compressor C301 A/B prediksi akan menurunkan 5\% discharge pressurenya. Discharge Pressure dan Discharge Flow perlu di monitor mengikuti requirement next process dari C302A/C. Nilai Discharge Pressure C303A/B perlu dijaga diatas 1100 Psig untuk memberikan hasil produksi yang optimum.

- Implementasi dari analisis persamaan regresi ini, Sumur FS di salah satu Anjungan Offshore Kalimantan Timur dengan tingkat kepercayaan yang tinggi untuk diturunkan suction pressure dari sebelumnya rata-rata 35 sampai dengan 40 Psig menjadi rata-rata 20 sampai dengan 25 Psig dengan hasil peningkatan produksi minyak di sumur FS sebesar 59 barrel per hari dan peningkatan produksi gas 1.5 
MMSCFD ( setara dengan 39 milyar rupiah per tahun).

\section{SARAN}

Penelitian ini dapat kembangkan lebih lanjut dengan memasukkan parameter input gas yang mempengaruhi unjuk kerja compressor multistage sehingga hasil yang diperoleh akan lebih bagus dan akurat.

\section{UCAPAN TERIMA KASIH}

Penulis mengucapkan terima kasih kepada semua pihak yang telah memberi dukungan terhadap penelitian ini.

\section{DAFTAR PUSTAKA}

Lesik,Sally,A.,2018, Applied Statistical Inference with Minitab,New Britain,Connecticut,USA.

Rath and Strong., 2006, Six Sigma Advance Tools Pocket Guide.AON

Ruggeri, Fabrizio et.al.,2007, Encyclopedia of Statistics in Quality and Reliability. Ist Edition Wiley.

Wang, Feng , Carnevale,M.,2018 Simulation of Multistage Compressor at Off-Design Condition. Volume 140.Journal of Turbomachinery. 